\title{
Apple Flavonoids Suppress Carcinogen-Induced DNA Damage in Normal Human Bronchial Epithelial Cells
}

\author{
Vazhappilly Cijo George ${ }^{1}$ and H. P. Vasantha Rupasinghe ${ }^{1,2}$ \\ ${ }^{1}$ Department of Plant, Food, and Environmental Sciences, Faculty of Agriculture, Dalhousie University, Truro, NS, Canada \\ ${ }^{2}$ Department of Pathology, Faculty of Medicine, Dalhousie University, Halifax, NS, Canada
}

Correspondence should be addressed to H. P. Vasantha Rupasinghe; vrupasinghe@dal.ca

Received 4 January 2017; Accepted 2 May 2017; Published 18 June 2017

Academic Editor: Debasish Roy

Copyright (c) 2017 Vazhappilly Cijo George and H. P. Vasantha Rupasinghe. This is an open access article distributed under the Creative Commons Attribution License, which permits unrestricted use, distribution, and reproduction in any medium, provided the original work is properly cited.

\begin{abstract}
Scope. Human neoplastic transformation due to DNA damage poses an increasing global healthcare concern. Maintaining genomic integrity is crucial for avoiding tumor initiation and progression. The present study aimed to investigate the efficacy of an apple flavonoid fraction (AF4) against various carcinogen-induced toxicity in normal human bronchial epithelial cells and its mechanism of DNA damage response and repair processes. Methods and Results. AF4-pretreated cells were exposed to nicotine-derived nitrosamine ketones (NNK), NNK acetate (NNK-Ae), methotrexate (MTX), and cisplatin to validate cytotoxicity, total reactive oxygen species, intracellular antioxidants, DNA fragmentation, and DNA tail damage. Furthermore, phosphorylated histone ( $\gamma$-H2AX) and proteins involved in DNA damage (ATM/ATR, Chk1, Chk2, and p53) and repair (DNA-PKcs and Ku80) mechanisms were evaluated by immunofluorescence and western blotting, respectively. The results revealed that AF4-pretreated cells showed lower cytotoxicity, total ROS generation, and DNA fragmentation along with consequent inhibition of DNA tail moment. An increased level of $\gamma$-H2AX and DNA damage proteins was observed in carcinogen-treated cells and that was significantly $(p \leq 0.05)$ inhibited in AF4-pretreated cells, in an ATR-dependent manner. AF4 pretreatment also facilitated the phosphorylation of DNA-PKcs and thus initiation of repair mechanisms. Conclusion. Apple flavonoids can protect in vitro oxidative DNA damage and facilitate repair mechanisms.
\end{abstract}

\section{Introduction}

Mammalian genomic DNA is susceptible to various environmental, cytotoxic, or genotoxic agents that sense DNA damage and activate signaling cascades for effective repair mechanisms. Under a normal circumstance with a specific type of DNA lesion, DNA damage is commonly repaired through nonhomologous end joining (NHEJ)/homologous recombination (HR) mechanisms $[1,2]$. Alkylating agents, platinum drugs, antimetabolites, topoisomerase inhibitors and ionizing radiations, nitrosoureas, aziridine compounds, alkyl sulphonates, and triazine compounds are some of the electrophiles that covalently transfer alkyl-groups onto the DNA bases, disrupting the DNA helix and induces DNA breaks [3]. DNA double-strand breaks (DSBs) are the most lethal lesions that can result in mutations, chromosomal aberrations, and cell death $[4,5]$. Extensive DNA damage and defects in repair systems can lead to poor genomic stability and initiate cardiovascular disease and cancer $[2,6]$. Hence, maintaining genomic integrity possess global healthcare challenge and should be well addressed.

An increased level of oxidative stress often causes excessive reactive oxygen species (ROS) generation, which breaks the equilibrium of metabolic process of normal cells and initiates DSBs [7]. As a result, the cells activate DNA damage response (DDR) mechanisms and initiate various enzymes that modify the DNA and nuclear damage. Recruitment of phosphatidylinositol-3-kinase (PI3K) family members to the site of DNA damage is the first step of DDR mechanisms, and the phosphorylation of ataxia telangiectasia-mutated (ATM) or ATM-Rad3-related (ATR) kinases are often followed in DDR process [8]. The phosphorylation of ATM/ATR regulates downstream targets including cell cycle check point kinases (Chk2/Chk1), tumor suppressor p53, 
and phosphorylated histone $\gamma$-H2AX foci, commonly known as a marker for DSBs [9]. $\gamma$-H2AX foci serve as a platform for the assembly and recruitment of other DNA repair factors, including mediators of DNA damage check point 1 (MDC1) to initiate DDR mechanisms [10]. DNA-dependent protein kinases (DNA-PK), composed of Ku70/80 heterodimer and a catalytic subunit (DNA-PKcs), serve as the pinnacle protein that cooperates with ATR/ATM to phosphorylate other proteins involved in the DNA damage $[11,12]$. Upon phosphorylation in serine and threonine residues (T2609, T3950, and S2056), DNA-PK initiates NHEJ repair mechanisms which are found to be very common in mammalian cells [4]. DNA-PK also gets autophosphorylated and expressed differentially in normal and malignant human tissues with relatively little variation in level [13]. However, there are many other proteins involved in this complex mechanisms and their roles are still inconclusive.

Development of effective nutraceuticals from natural resources has been major research endeavors over the past decade. While several reports are available to show the protective effects of various plant flavonoids and extracts against different genotoxicity [14], to the best of our knowledge, there are no specific studies available to show the mechanism of action of apple flavonoids to exert protection against DNA damage in normal human cells. Our previous studies have shown that an apple peel flavonoid fraction (AF4) possess antioxidant, neuroprotective, anti-inflammatory, and anticancer activities in various in vitro and in vivo models [15-17]. Moreover, AF4 is highly rich with flavonoids and phenolic acids such as quercetin glycosides, cyanidin 3galactoside, epicatechin, phloridzin, and chlorogenic acid [17]. In light of these findings, we hypothesized that AF4 could possibly render protection against DNA damage induced by various chemicals or environmental agents, whose primary target is inevitably airway epithelial cells in the lung. To test this hypothesis, we investigated the effects of AF4 on normal human bronchial epithelial cells (BEAS-2B) challenged with known carcinogenic chemical agents such as 4-(methylnitrosamino)-1-(3-pyridyl-d4)-1-butanone (NNK), 4-[(acetoxymethyl) nitrosamino]-1-(3-pyridyl)-1-butanone (NNK acetate; NNK-Ae), methotrexate (MTX), and cisplatin. We also analyzed the signaling proteins involved in DNA damage pathways since understanding the DNA repair mechanisms has important implication in developing a potent therapeutic agent.

\section{Material and Methods}

2.1. Chemicals, Kits, and Antibodies. Bronchial Epithelial Cell Growth Medium (BEGM) for BEAS-2B cells was purchased from Lonza (Walkersville, MD, USA). COMET SCGE assay kit was purchased from ENZO (New York, NY, USA). Cellular DNA fragmentation ELISA kit was purchased from Roche Diagnostics (Berlin, Germany). For immunofluorescence studies, anti-H2AX primary antibody (S139) was obtained from Millipore (Etobicoke, ON, Canada) and secondary antibody Alexa Flour 594 donkey anti-mouse from Life Tech (Carlsbad, CA, USA). Bicinchoninic acid (BCA) protein assay kit was purchased from Thermo Scientific (Chelmsford, MA,
USA). The total antioxidant capacity (TAC) kit was purchased from Biovision (Milpitas, CA, USA). Antibodies for DNA-PK, p-ATM, p-ATR, p-Chk1, p-Chk2, p-H2AX, p-P53, Ku80, SOD1, catalase, GPX1, and beta-actin were purchased from Cell Signaling Technology (Danvers, MA, USA). p-DNA-PKcs antibody was purchased from Abcam (Toronto, ON, Canada). DNA-PK inhibitor [NU7026; (2(morpholin-4-yl)-benzo[h]chomen-4-one)] was purchased from Sigma-Aldrich (Oakville, ON, Canada). NNK and NNK-Ae were purchased from Toronto Research Chemicals (Toronto, ON, Canada). Cisplatin, MTX, and NP-40 were purchased from Sigma-Aldrich (Oakville, ON, Canada). Apple flavonoid fraction (AF4) was isolated from apple peels as described previously [14]. Stock solutions were prepared in $100 \%$ dimethyl sulfoxide (DMSO), and the final concentrations never exceeded $0.5 \%(v / v)$ in culture treatment medium.

2.2. Cell Culture. Normal human bronchial epithelial cells (BEAS-2B) were purchased from American Tissue Type Culture Collection (ATCC; CRL-9609) and were cultured in BEGM media at $37^{\circ} \mathrm{C}$ in a humidified incubator with $5 \%$ $\mathrm{CO}_{2}$. Cells were cultured on polystyrene $\mathrm{T} 75\left(75 \mathrm{~cm}^{2}\right)$ culture flasks, precoated with a mixture of $0.01 \mathrm{mg} / \mathrm{mL}$ fibronectin, $0.03 \mathrm{mg} / \mathrm{mL}$ bovine collagen type $\mathrm{I}$, and $0.01 \mathrm{mg} / \mathrm{mL}$ bovine serum albumin dissolved in BEBM (basal) medium for overnight. Cells were grown to $\sim 70 \%$ confluence during all experimental conditions and were used from early passages $(<10)$ and within exponential growth phase.

2.3. Cell Viability by MTS Assay. Cell Titer $96^{\mathrm{TM}}$ aqueous cell viability assay (MTS) [18] was used to perform the viability of BEAS-2B cells under different treatment conditions. In order to find out the sublethal dose for AF4, a dose-dependent preliminary assay for various concentrations of AF4 was performed for $24 \mathrm{~h}$. Similarly, the dose-response effect for various carcinogens (NNK, NNK-Ae, cisplatin, and MTX) was also standardized using this assay. For cytoprotection analysis, $1 \times 10^{4}$ cells were plated on a 96-well plate with media of $150 \mu \mathrm{L} /$ well. After $24 \mathrm{~h}$, cells were either pretreated with AF4 $(50 \mu \mathrm{g} / \mathrm{mL})$ prior to different carcinogen treatments $(200 \mu \mathrm{M}$ NNK; $100 \mu \mathrm{M}$ NNK-A; $10 \mu \mathrm{M}$ cisplatin; and $200 \mu \mathrm{M}$ MTX) or alone with carcinogens for additional $24 \mathrm{~h}$. Fifteen microliters of MTS reagent (with PMS) was then added to each well and incubated further $3 \mathrm{~h}$ at dark. Absorbance was recorded at $490 \mathrm{~nm}$ using a microplate reader (Infinite ${ }^{\circledR} 200$ PRO, TECAN, Switzerland). DMSO control cells which are devoid of any treatments and cells containing only culture medium and MTS reagent served as the blank for each experiment.

2.4. Measurement of Intracellular ROS. The ROS level was measured in BEAS-2B cells after treatments as described previously [19]. 2',7'-Dichlorofluorescin diacetate (DCFH-DA) is readily taken up by cells and is subsequently hydrolyzed to DCFH, which can be oxidized to measurable fluorescent product dichlorofluorescein (DCF). AF4-pretreated cells (for $1 \mathrm{~h}$ ) were exposed to $3 \mathrm{~h}$ of carcinogens or alone in different experimental groups. Cells with only DMSO media 
served as the vehicle control. After treatments, DCFH-DA was added to the cell culture plates at a final concentration of $5 \mu \mathrm{M}$ followed by $40 \mathrm{~min}$ incubation at dark. The fluorescence degradation was then measured at an excitation wavelength of $490 \mathrm{~nm}$ and an emission wavelength of $510 \mathrm{~nm}$ by using Infinite 200 PRO, TECAN, Switzerland. The results were expressed as relative total ROS level with respect to DMSO control.

2.5. Total Antioxidant Capacity (TAC). A colorimetric-based method was used to measure intracellular TAC, according to the manufacturer's instructions with slight modification. Briefly, the total cell lysate was prepared after treatments in NP-40 lysis buffer ( $5 \mathrm{M} \mathrm{NaCl}, 1 \mathrm{M}$ Tris, $10 \% \mathrm{NP}-40)$. Each sample was added with $100 \mu \mathrm{L}$ of freshly prepared $\mathrm{Cu}^{2+}$ working solution and incubated for $1.5 \mathrm{~h}$ at dark. The reduction $\left(\mathrm{Cu}^{2+}\right.$ to $\left.\mathrm{Cu}^{+}\right)$reaction was then measured at $570 \mathrm{~nm}$ by using Infinite 200 PRO, TECAN, Switzerland. Trolox was used as the standard to quantify the TAC of the tested samples, and the results were expressed in Trolox equivalence.

2.6. $\gamma$-H2AX Immunofluorescence Assay. Immunofluorescence method [20] was used to measure the DNA damage at histone level by quantifying $\gamma$-H2AX foci in BEAS-2B cells. Briefly, $2 \times 10^{5}$ cells were seeded on a coated cover slip placed in a 6 -well plate with $24 \mathrm{~h}$ incubation. For experimental setup, the cells were then treated with AF4 alone for $1 \mathrm{~h}$ or prior to each carcinogen treatment for $3 \mathrm{~h}$ (same treatment conditions were maintained for all following experiments). DMSO media served as a control for each test sample. After treatments, cells were washed thoroughly with PBS and fixed in $3.7 \%$ formaldehyde for $20 \mathrm{~min}$ at dark. The cells were then permeabilized with $0.5 \%$ Triton X-100 in PBS for $15 \mathrm{~min}$ on a rocker at room temperature followed by blocking with $4 \% \mathrm{BSA}$ for $20 \mathrm{~min}$. The cells were incubated with primary antibody $(1: 250)$ for $1 \mathrm{~h}$ at room temperature, washed three times with PBS, and then incubated with secondary antibody $(1: 500)$ for $45 \mathrm{~min}$. After washing the cells three times in PBS, coverslips were carefully transferred into slides and mounted by using wet-mounting medium, Vectashield ${ }^{\circledR}$ containing DAPI and sealed with nail polish. The fluorescent images were then captured by using a microscopy (ZEISS, $\mathrm{X}$-Cite series $120 \mathrm{PC}$ ) at 100x magnification.

2.7. DNA Fragmentation Analysis. DNA fragmentation in BEAS- $2 \mathrm{~B}$ cells was measured by cellular DNA fragmentation ELISA kit [21] as per the supplier's instructions. In short, BEAS-2B cells were labeled with $10 \mu \mathrm{M}$ bromodeoxyuridine (BrdU) at $1 \times 10^{5}$ cells $/ \mathrm{mL}$ density. Hundred microliters of BrdU-labelled cells in culture medium were treated as per above-mentioned conditions. The cells were then lysed with lysis buffer, and apoptotic DNA fragments in supernatants were collected for each sample after centrifugation at $270 \mathrm{~g}$ for $10 \mathrm{~min}$. Hundred microliters of the sample was then transferred to precoated anti-DNA 96-well, flat-bottom microplates with incubation for $90 \mathrm{~min}$ at $25^{\circ} \mathrm{C}$. The DNA was then denatured by microwave irradiation $(500 \mathrm{~W}$ for $5 \mathrm{~min}$ ) followed by the addition of $100 \mu \mathrm{L}$ anti-BrdU-POD conjugate solution with additional $90 \mathrm{~min}$ of incubation.
The plates were washed by three times with wash buffer (1x), and $100 \mu \mathrm{L}$ of substrate (TMB) solution was then added for color development. Twenty-five microliters of stop solution was added after $5 \mathrm{~min}$, and the plates were read at $450 \mathrm{~nm}$ using a microplate reader (Infinite 200 PRO, TECAN, Switzerland).

2.8. Comet Assay. The comet assay was performed to measure the DNA tail moment as per kit instructions with minor modifications. After treatments, $1 \times 10^{5}$ cells were combined with molten LMA (low melting agarose) at a ratio of $1: 10$ $(v / v)$ and $75 \mu \mathrm{L}$ of each sample was pipetted on to a comet slide and incubated in dark at $4^{\circ} \mathrm{C}$ for $20 \mathrm{~min}$. The slides were then immersed in cold lysis buffer at $4^{\circ} \mathrm{C}$ for $45 \mathrm{~min}$ followed by alkaline treatment $(300 \mathrm{mM} \mathrm{NaOH}, 1 \mathrm{mM}$ EDTA, $\mathrm{pH}>13$ ) for additional $45 \mathrm{~min}$ in dark. The slides were washed with TBE buffer (1x) for $5 \mathrm{~min}$ and subjected to horizontal electrophoresis conditions $(1 \mathrm{~V} / \mathrm{cm}$ for $10 \mathrm{~min})$. The slides were air-dried after dipping in $70 \%$ ethanol for $5 \mathrm{~min}$, stained with CYGREEN ${ }^{\circledR}$ dye $(1: 1000)$, and examined under epifluorescence microscopy (ZEISS, X-Cite series 120 PC; Toronto, ON, Canada) with 40x magnification (excitation/ emission $489 / 515 \mathrm{~nm}$ ). The comets were scored by commercially available software, OpenComet (http://www.cometbio .org), and a minimum of 50 cells was quantified by measuring percentage DNA tail moment.

2.9. Western Blotting. The cells were harvested after the treatments and were lysed using $1 \times$ SDS lysis buffer $(1 \mathrm{mM}$ Tris$\mathrm{HCl}$ [pH 6.8], $2 \% w / v$ SDS, $10 \%$ glycerol) under reduced conditions on the ice. Total protein concentration in each sample was measured by using BCA protein assay kit. A total of $25 \mu \mathrm{g}$ of protein samples were loaded on $4-12 \%$ SDS-PAGE gel and electro-transferred to a nitrocellulose membrane. The membrane was then blocked with 5\% nonfat milk solution, probed with specific primary antibodies $(1: 1000)$ for overnight incubation, washed and reprobed with respective secondary antibodies $(1: 2000)$ for $45 \mathrm{~min}$, and then developed by enhanced chemiluminescence (ECL) method using Chemidoc MP (Bio-Rad, Mississauga, ON, Canada). Protein expression of each band was normalized with respective actin level, and relative protein expression was quantified with respect to untreated control bands for each experiment.

2.10. Statistical Analysis. All the experiments were performed in triplicates $(n=3)$ and for at least three independent times and analyzed by two-tailed Student's $t$-test by using GraphPad Prism software (GraphPad Software Inc., San Diego, CA, USA). Data were presented as mean \pm standard deviation (SD), and $p$ values $\leq 0.05$ were considered as significant between experimental groups.

\section{Results}

3.1. Cell Viability and Cytoprotective Effects of AF4. In order to realize the sublethal dosage for AF4, preliminary doseresponsive effects on the viability of BEAS- $2 \mathrm{~B}$ cells were studied using MTS assay. A dose-responsive decline in cell viability was observed in BEAS-2B cells with increasing concentrations of AF4, especially at 100 and $200 \mu \mathrm{g} / \mathrm{mL}$ 

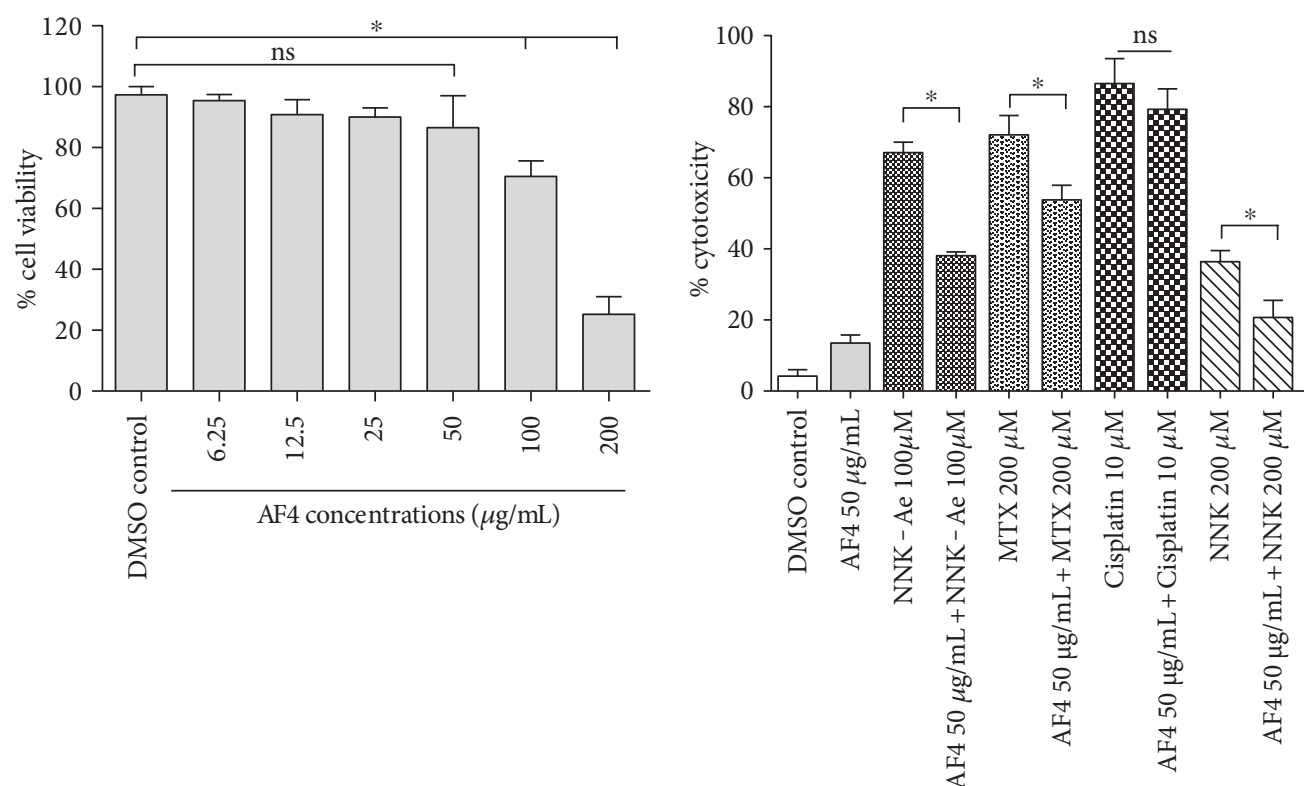

(a)

(b)

Figure 1: (a) Dose-dependent effect of AF4 on BEAS-2B cells after $24 \mathrm{~h}$ of treatment. (b) Cytoprotective effects of AF4 against various carcinogens challenged after $24 \mathrm{~h}$ of treatment. Experimental values presented as mean $\pm \mathrm{SD}$ of $n=3$ independent experiments. $*$ indicated statistical difference at $P \leq 0.05$. ns: nonsignificant.

(Figure 1(a)). However, over $\geq 80 \%$ cell viability was observed up to $50 \mu \mathrm{g} / \mathrm{mL}$ concentrations of AF4 and hence taken for evaluating protective effects in further experiments. Our previous studies have also shown that $50 \mu \mathrm{g} / \mathrm{mL}$ of AF4 did not alter cell viabilities of three primary normal cells treated for 24 and $48 \mathrm{~h}$ [17]. DMSO control in all experiments showed $\leq 5 \%$ cytotoxicity. After $24 \mathrm{~h}$ of treatments with each carcinogen, we observed a higher cytotoxicity (>50\%) for $10 \mu \mathrm{M}$ of cisplatin, $200 \mu \mathrm{M}$ of MTX, and $100 \mu \mathrm{M}$ of NNK-Ae (Figure 1(b)). Cisplatin exhibited a very high cytotoxicity $(>80 \%)$ among the carcinogens studied. However, NNK did not show higher cytotoxicity for BEAS-2B cells $(<50 \%)$. Likewise, for studying cytoprotective effects of AF4, we initially treated BEAS-2B cells with AF4 $(50 \mu \mathrm{g} / \mathrm{mL})$ prior to each carcinogen exposure. AF4 pretreatment showed significant $(p \leq 0.05)$ reduction in cytotoxic level for NNK-Ae, MTX, and NNK exposed cells when compared to their treatments alone. In contrast, AF4 pretreatment did not show any significant reduction in cytotoxicity for cisplatin-treated cells and found to be morphologically distinct with rounded-shape or detached cells (data not shown).

3.2. ROS Mitigating and Antioxidant Potentials of AF4. Excessive ROS is one of the primary factors that can initiate DNA damage in healthy cells [22]. ROS level was studied either with AF4 alone or with carcinogen-treated BEAS-2B cells, and the data is shown in Figure 2(a). All the carcinogen-treated cells showed an almost two-fold increase in relative to total ROS (DMSO control) levels when compared to AF4-treated cells. Pretreatment with AF4 prior to each carcinogen exposure significantly $(p \leq 0.05)$ reduced ROS levels in these cells. Interestingly, in all the AF4 preexposed cells, we observed similar levels of ROS despite each carcinogen tested in the study.

Antioxidants are well-known for their capacity to mitigate ROS generation, especially under oxidative stress, which is considered as the primary event in many diseases [23]. We assessed the antioxidant enzymes [superoxide dismutase (SOD), glutathione peroxidase (GPX), and catalase] (Figure 2(b)) and TAC (Figure 2(c)) in BEAS-2B cells after treated with either AF4 alone or with carcinogens. Preexposure of AF4 showed an increased SOD1 expression in NNK-Ae or MTX-treated samples when compared to their controls. However, both catalase and GPX levels remained almost the same in all the tested groups. TAC in AF4 preexposed groups showed greater antioxidant capacity than carcinogens alone. The findings indicate that AF4 has enhanced intracellular antioxidant potential.

3.3. AF4 Inhibits DNA-Histone Protein Damage. $\gamma$-H2AX immunofluorescence assay was used to analyze the DNA damage at histone level after each treatment conditions, and the results are shown in Figure 3(a). DAPI was used to stain the nucleus (blue color) colocalized with $\gamma$-H2AX foci, which appeared as red color when observed under fluorescence microscope. Cisplatin-, NNK-Ae-, or MTX-treated groups exhibited severe damage at histone level (S 139) when compared to DMSO control cells. Treatment with AF4 did not cause any increase in histone damage level when compared to DMSO control cells. Quantification of data (Figure 3(b)) showed that pretreatment with AF4 significantly $(p \leq 0.05)$ inhibited $\gamma$-H2AX damage (foci/nucleus) level caused by NNK-Ae or MTX exposure. The DNA damage caused by cisplatin could not able to reduce by preexposure to AF4. As observed in other assays, cisplatin showed the 


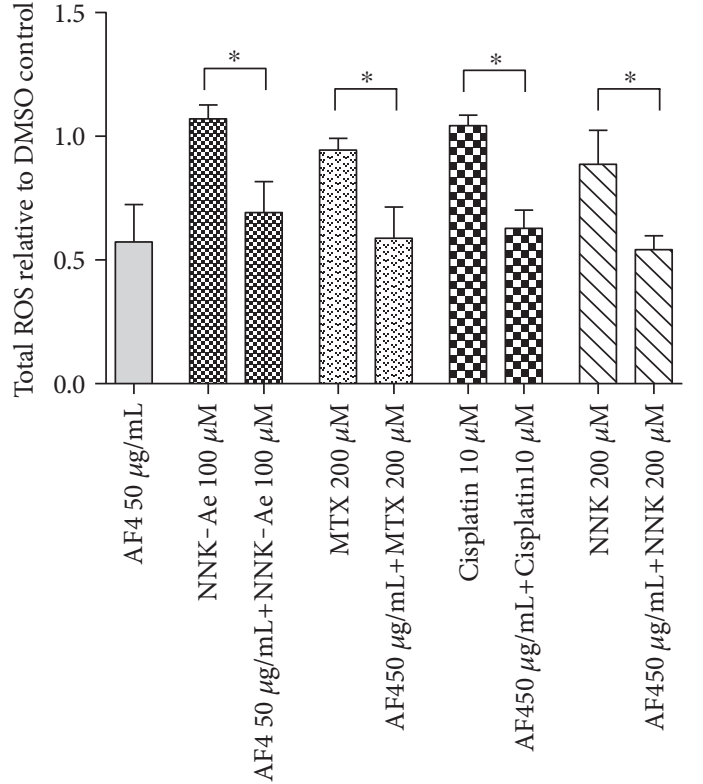

(a)
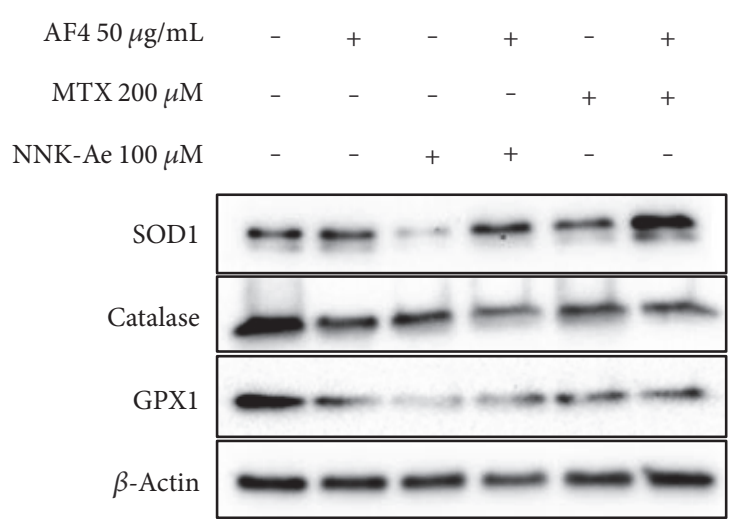

(b)

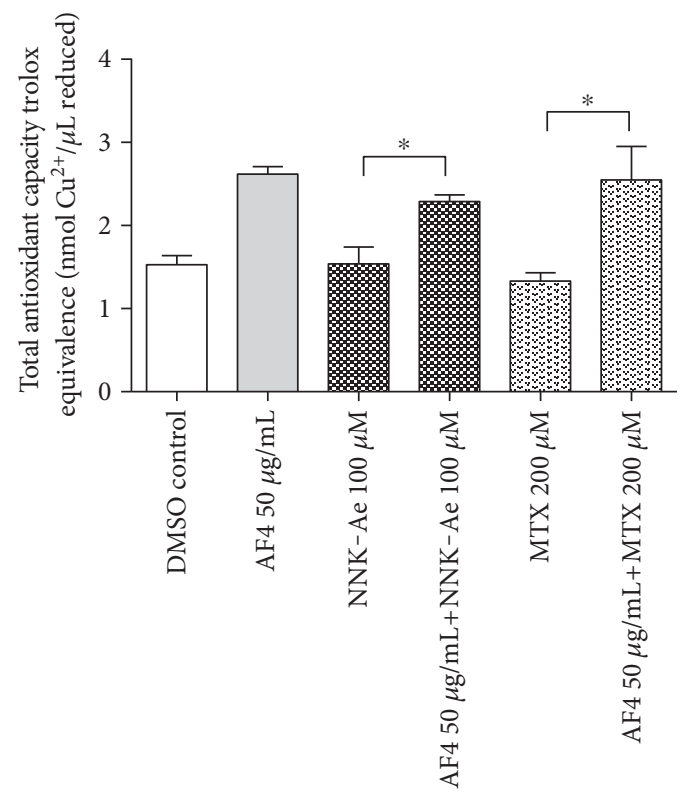

(c)

FIGURE 2: (a) The relative amount of ROS assessed on BEAS-2B cells after exposed to either carcinogen alone or with pretreatment of AF4. (b) Effects of AF4 on intracellular antioxidant enzymes (SOD1, catalase, and GPX1) along with carcinogen-treated groups as shown by western blotting. Beta-actin is used as in internal control to demonstrate equal protein in all tested samples. (c) TAC of BEAS-2B cells after various treatments was measured by a colorimetric kit-based method and showed in Trolox equivalence. Experimental values presented as mean \pm SD of $n=3$ independent experiments. * indicated statistical difference at $P \leq 0.05$.

highest damage among all carcinogens tested. Cisplatin and NNK were therefore avoided from all the remaining studies since they are found to be either too toxic or less toxic, respectively, as observed from the $\gamma$-H2AX assay.

3.4. AF4 Protects DNA Fragmentation in BEAS-2B Cells. DNA fragmentation was considered as an early event that initiates the phosphorylation of $\mathrm{H} 2 \mathrm{AX}$ histone proteins at Serine 139 position [24]. To investigate whether AF4 protects severe toxic effects of NNK-Ae or MTX at DNA level, we used an ELISA method and the fragmentation levels are shown in Figure 4. OD at $450 \mathrm{~nm}$ corresponds to the DNA fragmentation levels in BEAS-2B cells. The treatment with NNK-Ae and MTX enhanced the DNA fragmentation levels when compared to DMSO control. We do observe some DNA fragmentation in AF4-treated cells but was found to be nonsignificant with respect to DMSO control. Pretreatment with AF4 significantly $(p \leq 0.05)$ reduced DNA fragmentation in both NNK-Ae- and MTX-treated groups and protect DNA integrity in these cells. 
DMSO Control

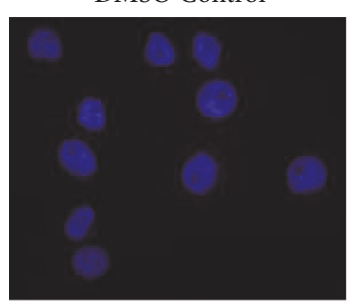

NNK-Ae

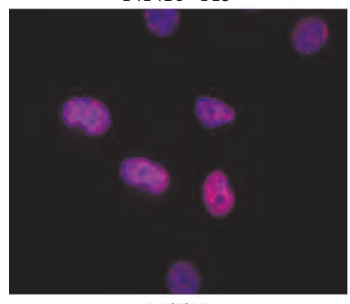

MTX

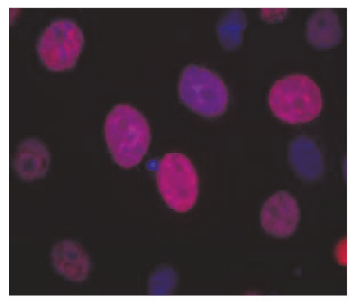

Cisplatin

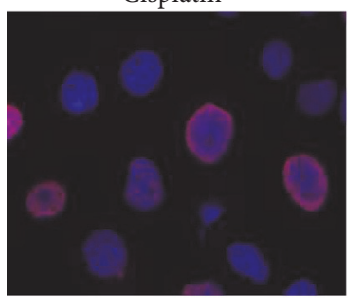

NNK

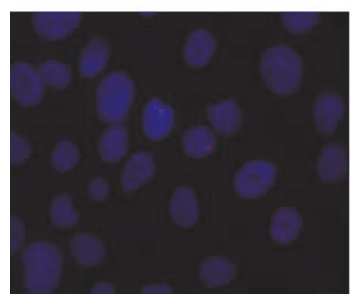

AF4

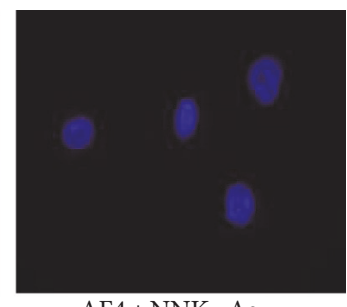

$\mathrm{AF} 4+\mathrm{NNK}-\mathrm{Ae}$

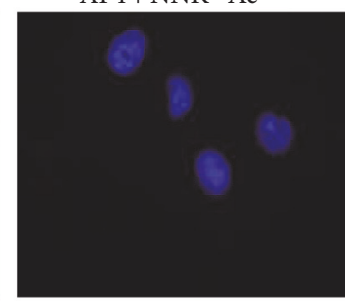

$\mathrm{AF} 4+\mathrm{MTX}$

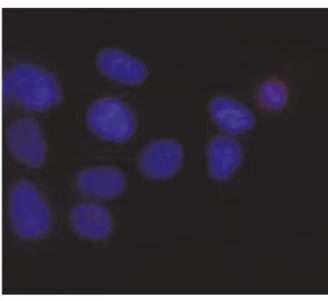

AF4 + Cisplatin

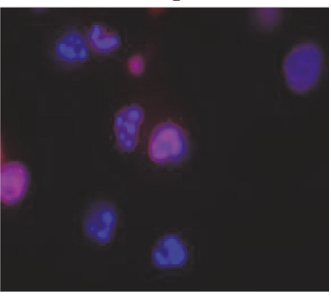

$\mathrm{AF} 4+\mathrm{NNK}$

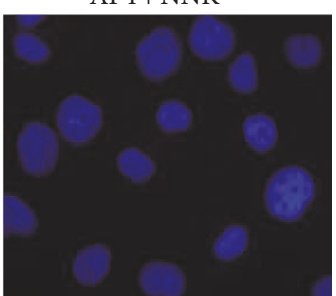

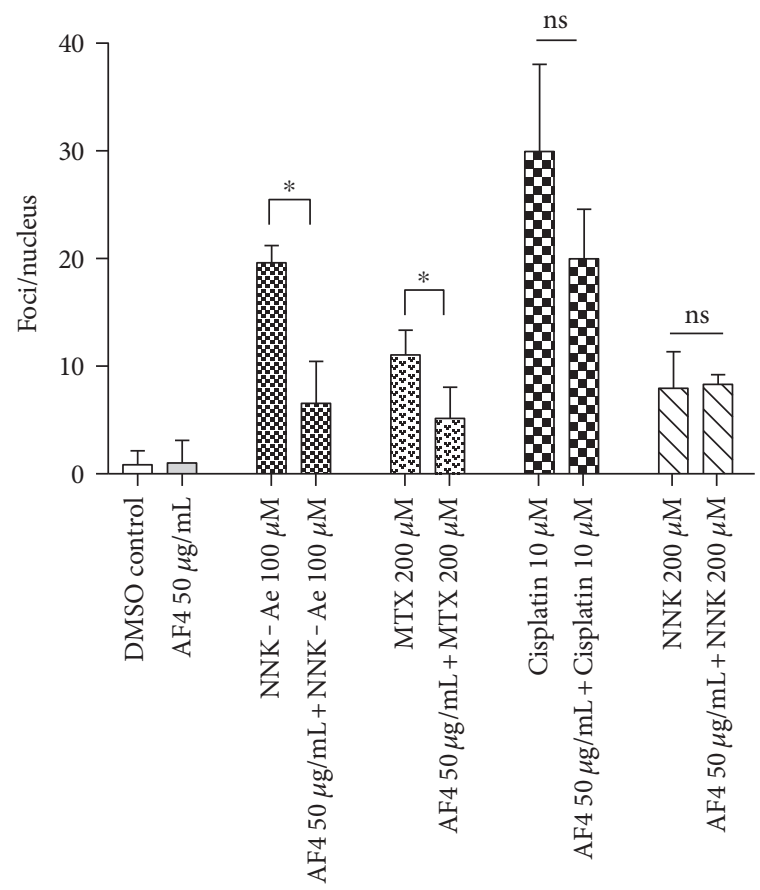

(b)

(a)

Figure 3: (a) BEAS-2B cells were exposed to either carcinogens alone or in combination with pretreatment of AF4 followed by immunofluorescence staining with $\gamma$ - $\mathrm{H} 2 \mathrm{AX}$ antibody and were captured by epifluorescence microscopy at 100x magnification. Nuclei were stained as blue and $\gamma$-H2AX foci (S 139) appeared as red. The image shown represents cells from three independent experiments. (b) Quantification of focus/nucleus ratio was calculated for each sample from at least 50 cells. * indicated statistical difference at $P \leq 0.05$.

3.5. Preexposure to AF4 Reduces DNA Tail Damage. Comet assay was used to measure the DNA strand breaks in an individual eukaryotic cell and got multiple applications such as monitoring environmental contamination with genotoxins, human biomonitoring and molecular epidemiology, DNA damage, and repair studies [25]. After the treatments, DNA tail damage was evaluated as the migration of DNA from the nucleus and the data was quantified and depicted in Figures 5(a) and 5(b). Untreated cells (DMSO control) and AF4-treated cells retained their cellular integrity, and their percentage tail damage were $<15 \%$. Similar results were also observed for untreated PC12 neuronal cells [26]. BEAS-2B cells treated with either NNK-Ae or MTX showed a higher percentage of DNA damaged tails (97.4\% and 68.0\%, respectively), and AF4 pretreatment significantly $(p \leq 0.05)$ reduced the length of percentage tail damage, as quantified from at least 50 comet cells. NNK-Ae-treated cells showed the highest DNA tail damage compared to MTX treatment at identical concentration and time.

3.6. AF4 Inhibits DDR Signaling and Facilitate Repair Mechanisms. We further investigated the mechanism of 


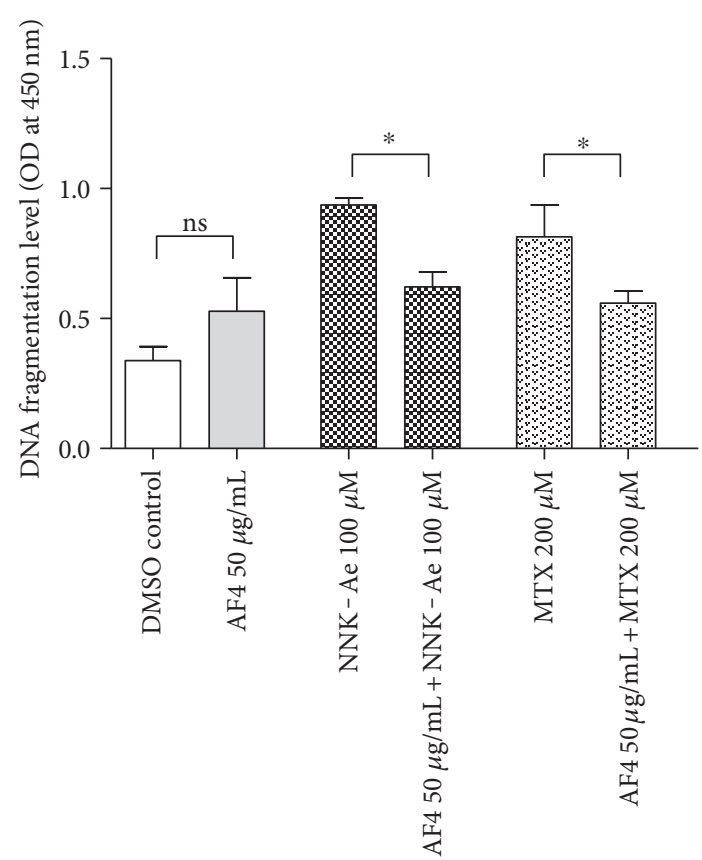

FIGURE 4: DNA fragmentation level in BEAS-2B cells after exposed to either carcinogen alone or in combination with pretreatment of AF4. OD at $450 \mathrm{~nm}$ corresponds to the amount of DNA fragments. Data expressed as mean $\pm \mathrm{SD}$ of $n=3$. * indicated statistical difference at $P \leq 0.05$.

action of AF4 to render protection against NNK-Ae- and MTX-induced toxicity in BEAS-2B cells by analyzing signaling proteins involved in DDR process. The phosphorylation levels of ATM, ATR, and DNA-PK were studied using western blotting (Figure 6). Cell cycle check point kinases Chk1 and Chk2 and tumor suppressor protein p53 were also analyzed and quantified (Figure 6). ATM/ATR mutations are the primary causes for DNA damage, and they act upstream of p53 sensors and sense DDR functions to the cells [9]. Treatment with NNK-Ae and MTX augmented DDR signaling and ATR phosphorylation (serine 428) in BEAS-2B cells with respect to control cells. However, we did not observe any phosphorylation of ATM protein at identical dosages and time. Expression of DNA-PK level was found to be the same with untreated control or carcinogen-treated cells. Interestingly, pretreatment with AF4 downregulated DNA-PK protein with respect to control cells. Effector proteins like Chk1, Chk2, and p53 were found to be phosphorylated in NNK-Ae-treated cells. In contrast, MTX treatment did not induce these signaling proteins. Pretreatment with AF4 showed significant $(p \leq 0.05)$ reduction in the phosphorylation of ATR, Chk1, and p-53 levels in NNK-Ae-treated cells. We also observed a significant inhibition of $\gamma$-H2AX protein in AF4-pretreated cells prior to NNK-Ae treatment. Overall, our data showed that pretreatment with AF4 significantly attenuates DDR proteins especially challenged against NNK-Ae genotoxicity.

Further, to investigate whether AF4 facilitates DNA repair mechanisms in vitro, we also tested for proteins such as p-DNA-PKcs and KU80 with AF4-pretreated cells prior to NNK-Ae treatment (Figure $7(\mathrm{a})$ ). Interestingly, AF4 reduced DNA-PK level either when treated alone or in combination with NNK-Ae but activates p-DNA-PKcs at the T2609 position. The phosphorylation level of DNA-PKcs was found to be comparatively higher in AF4-pretreated cells than in NNK-Ae-treated cells, indicating its DNA repairing potential. Further to confirm this, we have used NU7026 that inhibits DNA-PK protein expression [27]. Treatment with NU7026 on BEAS-2B cells for $20 \mu \mathrm{M}$ (30 min) almost eliminated DNA-PK protein in these cells (Figure 7(b)). An autophosphorylated DNA-PKcs protein was observed in untreated cells, and treatment with inhibitor reduces the DNA-PKcs level even in AF4-pretreated cells. This preliminary result further confirms that AF4 pretreatment will facilitate the cells to phosphorylate DNA-PKcs which is essential in NHEJ repair mechanism.

\section{Discussion}

Aberrant mutations in the genome of an organism caused by increased exposure to a carcinogen often lead to a condition called genomic instability. Even low-dose chemicals or environmental exposure can induce DNA damage especially when there is a failure in proper DNA repair mechanism [28]. Due to the excessive ROS, a disturbance in natural antioxidant defense system is expected with damage to all biomolecules, including nucleic acids. Antioxidant-rich diet and nutraceutical supplements can be a good therapeutic strategy to overcome oxidative nucleic acid damage [29]. Hence, in this study, we have evaluated the apple flavonoids, which are a rich source of antioxidants [17, 30, 31] against various carcinogen-induced DNA damage in BEAS-2B cells. We also aimed to study the underlying mechanism of AF4's effects in DDR and repair process followed by DNA damage.

Our previous studies have demonstrated the selective cytotoxicity of AF4 to induce cell death in cancer cells without altering physiological functions of normal cells, including primary human hepatocytes (NHEPS), primary rat hepatocytes (RTCP-10), and primary lung cells (WI-38) [17]. To expand this knowledge, we have analyzed the impact of different doses of AF4 on the viability of BEAS-2B cells and observed that $50 \mu \mathrm{g} / \mathrm{mL}$ maintains cellular integrity with more than $80 \%$ viability even after $24 \mathrm{~h}$ treatment. However, higher doses were found to reduce the viability considerably and also reported by others [32], suggesting the hormetic effects of dietary flavonoids [14,33]. Hence, we have chosen $50 \mu \mathrm{g} / \mathrm{mL}$ for evaluating the protective effects of AF4 in BEAS-2B cells. NNK, NNK-Ae, MTX, and cisplatin were used to induce DNA damage in BEAS-2B cells since we and others have observed that these carcinogens can significantly reduce cell viabilities of normal cells by enhancing ROS levels and cell death mechanisms $[34,35]$. Pretreatment of AF4 significantly reduced toxic effects of these carcinogens but not for cisplatin treatment. This could be because of an increased intracellular antioxidant enzyme (SOD and small molecules or proteins, as observed in AF4-pretreated groups, which could possibly play a role in scavenging these ROS and helped the cells to mitigate the oxidative stress. Flavonoids are well-known for their ROS scavenging potentials 
DMSO control

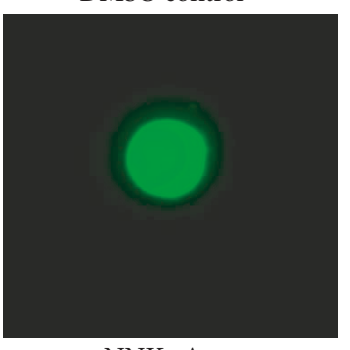

NNK-Ae

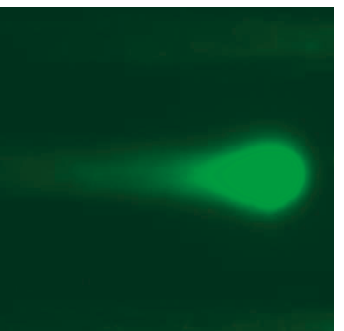

MTX

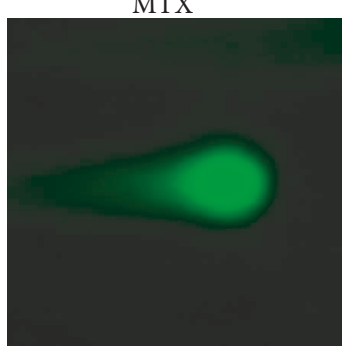

AF4

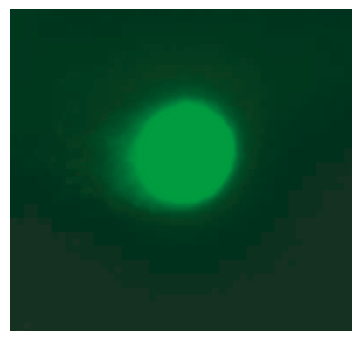

$\mathrm{AF} 4+\mathrm{NNK}-\mathrm{Ae}$

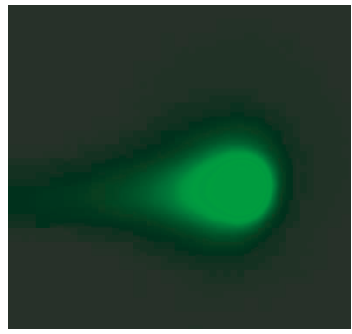

$\mathrm{AF} 4+\mathrm{MTX}$

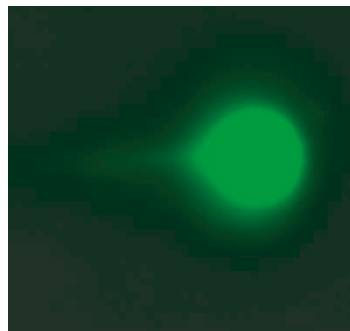

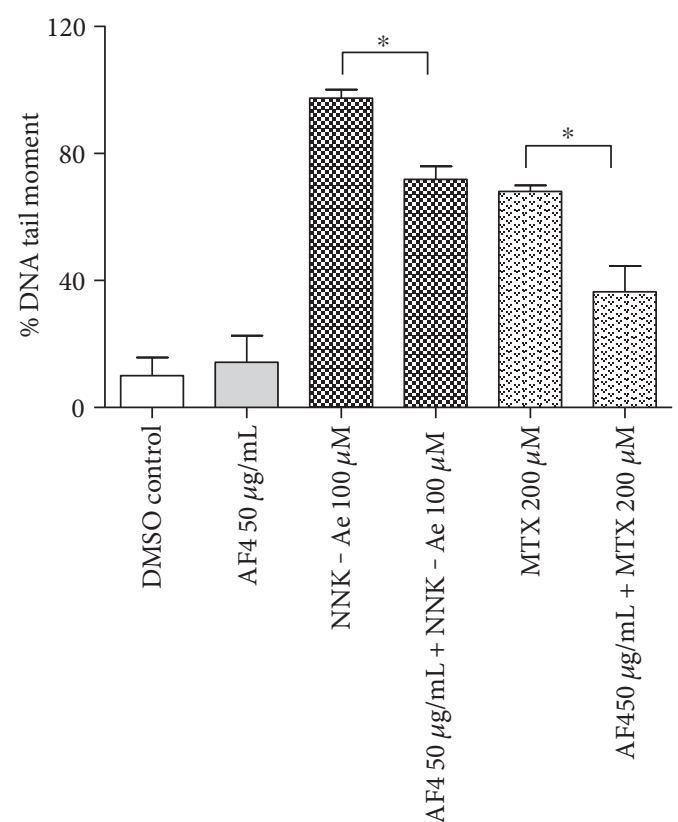

(b)

(a)

Figure 5: (a) DNA tail damage in BEAS-2B cells exposed to either carcinogen alone or in combination with pretreatment of AF4, as assessed by comet assay. (b) Quantification of DNA tail damage using OpenComet freeware. At least 50 comets for each sample were analyzed and examined with a fluorescence microscopy under 40x. Experimental values presented as mean \pm SD of $n=3$ independent experiments. * indicated statistical difference at $P \leq 0.05$.

$[14,36]$, and similar effects for apples were reported by many investigators $[15,16,31]$.

Histone posttranslational modifications are one of the earliest events in DSBs and are often characterized by remodeling of chromatin organization [37]. The carcinogens used in this study were observed to modulate posttranslational mechanisms of histone proteins even at $3 \mathrm{~h}$ of exposure. This observed toxicity could possibly due to the interstrand crosslink-induced DSBs that are produced at replication forks and are largely responsible for observed $\gamma$-H2AX foci in carcinogen-treated cells [38]. Each focus assumed to represent a single DSB [39]. However, pretreatment with AF4 inhibited the reorganization of histone variants that regulates DNA methylation. This could account for the similarities in protective effects of both at histone and DNA fragmentation, which appeared to be sensitive tools for analyzing DNA lesions. DNA fragmentation is considered as the hallmark of cell death mechanisms and an irreversible event that commits the normal cell to die [20]. AF4 was found to protect this phenomenon in BEAS-2B cells against NNK-Ae and MTX toxicity. Flavonoids are known to exhibit these protective potentials against various genotoxicity as evident from various studies [14, 29, 40,41]. The fragmentation level observed in untreated cells could be because of the normal mechanism of the body to dispose large fragments of DNA from dying cells, which may be critical in maintaining normal tissue homeostasis [42].

Consequently, quantitative analysis was carried out by using comet assay to understand the extent of DNA damage caused by carcinogenic factors. Increased comet tails indicated the induction of DSBs through excision followed by resynthesis and ligation of fragments. A significant inhibition of DNA tail damage was recorded in AF4-pretreated cells when compared to carcinogen treatments, further, substantiate the potential of AF4 to render DNA protection in BEAS-2B cells. Taken together, we speculate that these protective effects are mainly due to either AF4's antioxidant properties or its ability to stimulate DNA repair enzymes. Polyphenols such as luteolin, quercetin, and rosmarinic acid have shown similar effects to protect DNA damage against oxidative stress in neuronal cells $[14,26]$. A recent study has also shown that sesaminol, a lignin from sesame seeds with increasing activities of catalase and SOD, protects BEAS-2B cells against DNA damage caused from cigarette smoke extract [43]. All these studies confirm that plant polyphenols with antioxidant activity could counteract the toxic effects of carcinogens and may help to maintain genomic stability. 


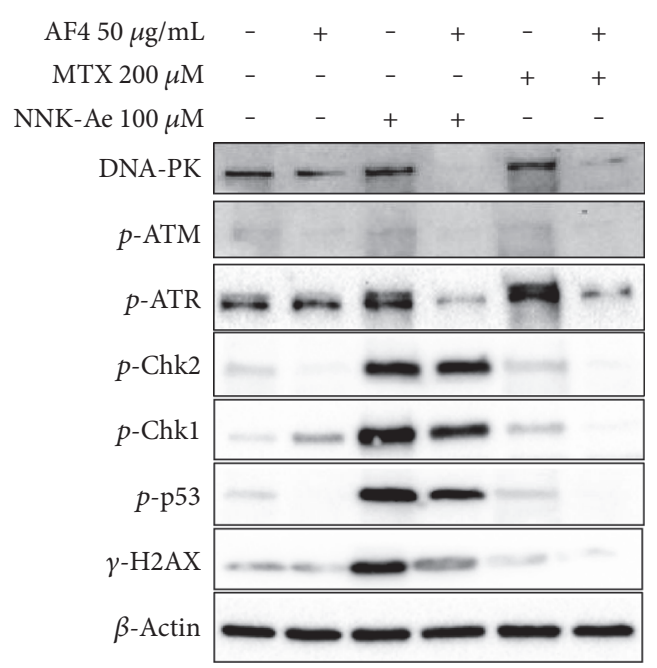

(a)

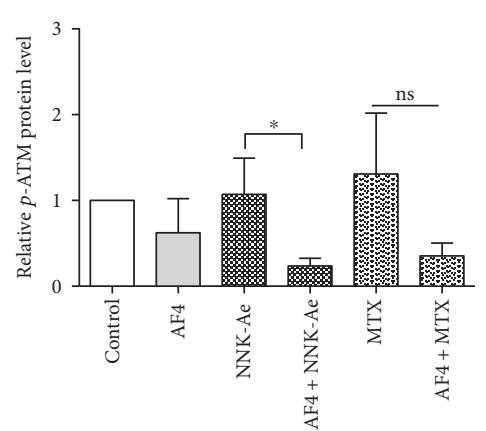

(c)

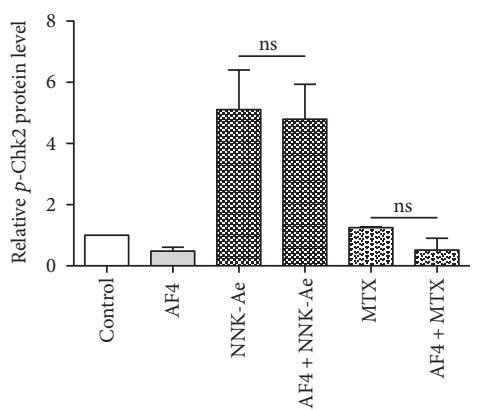

(e)

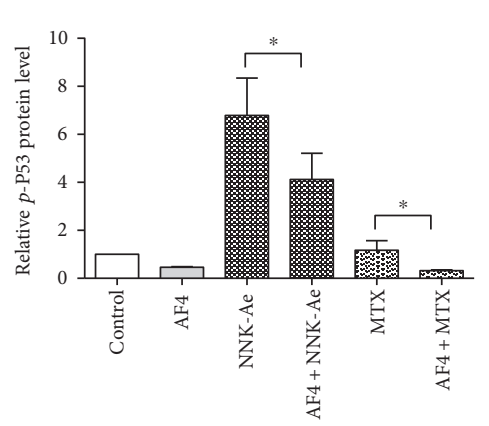

(g)

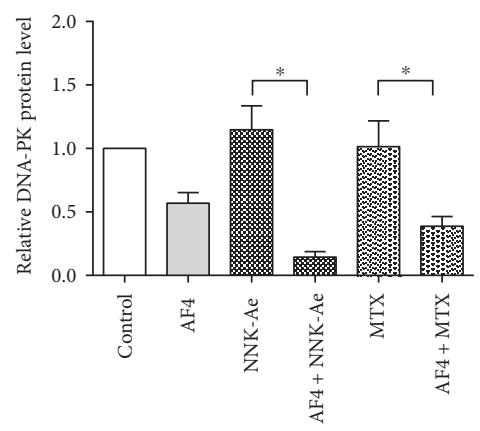

(b)

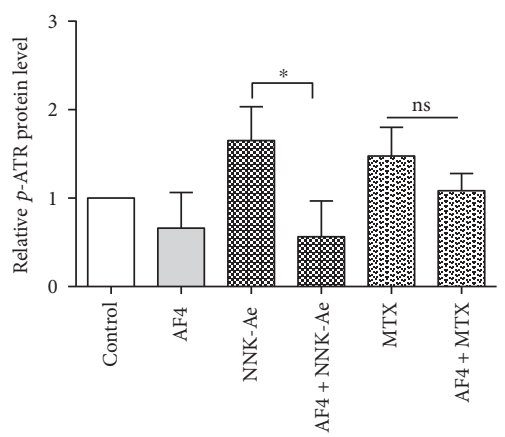

(d)

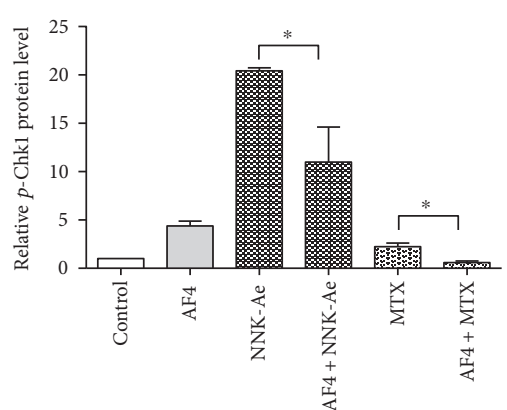

(f)

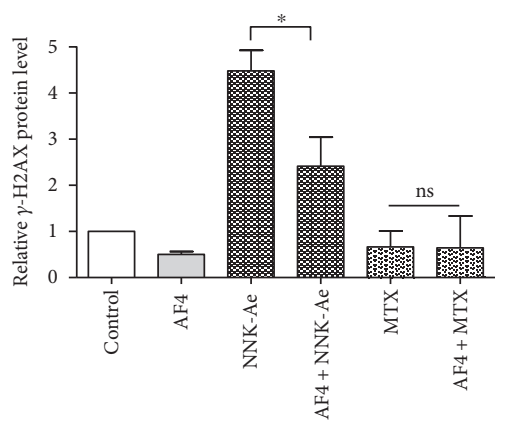

(h)

Figure 6: (a) Effects of AF4 on various DDR signaling proteins exposed to NNK-Ae or MTX as assessed by western blotting. (b), (c), (d), (e), (f), (g), and (h) The relative amount of each protein expression levels (DNA-PK, p-ATR, p-ATM, p-Chk2, p-Chk1, p-P53, and $\gamma$-H2AX) with respect to beta-actin loading control, quantified from at least 3 independent experiments. $*$ indicated statistical difference at $P \leq 0.05$ with mean \pm SD. ns: nonsignificant. 


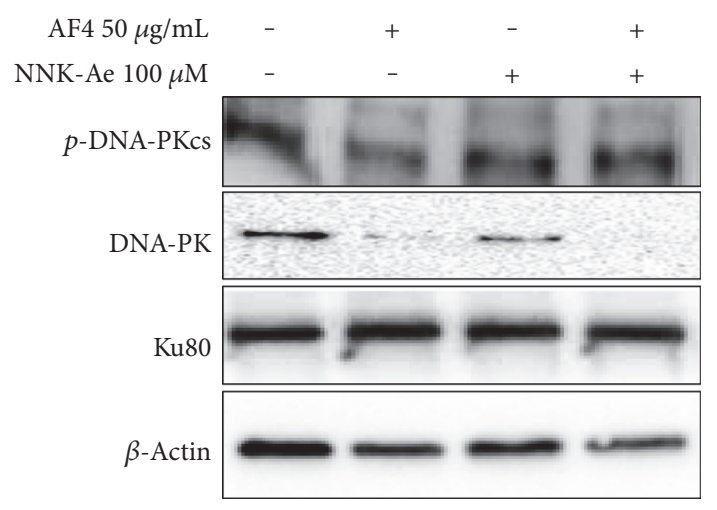

(a)

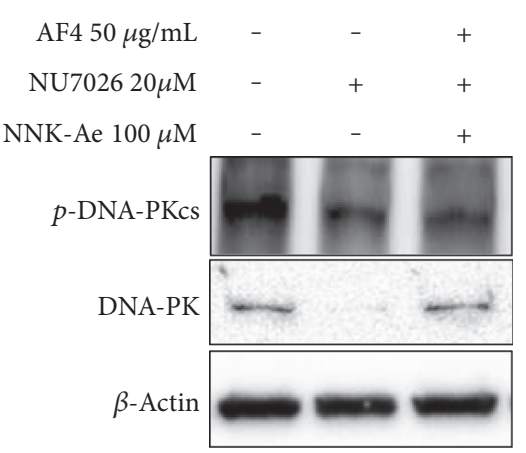

(b)

FIgURE 7: (a) Effects of AF4 on DNA repairing proteins (DNA-PK, p-DNA-PKcs, and KU80) challenged with NNK-Ae alone or in combination. (b) Inhibitory effect of NU7620 (20 $\mu \mathrm{M}$ for 30 mins) against DNA-PK expression on BEAS-2B cells treated alone or with a combination of AF4 and NNK-Ae.

In order to test our hypothesis, we further investigated the molecular mechanism of DSBs induced by NNK-Ae or MTX, since it is crucial to identify therapeutic targets during drug discovery process. The recruitment of DDR factors to DSBs was analyzed by immunoprobing against different proteins (ATM, ATR, DNA-PK, Chk1, Chk2, and p53). ATM/ ATR mutation plays a key role in surveillance of genomic integrity along with signal transducers [38]. ATM-Chk2 or ATR-Chk1 are the two common pathways that get activated during DSBs and ultimately triggers p53 [44]. Our data showed that NNK-Ae induces DSBs through the phosphorylation of ATR and not ATM in BEAS-2B cells. ATR is the major kinase activated during a replication stress and plays a key role in "S" phase cell cycle arrest [11]. Effector proteins such as Chk1, Chk2, and p53 also became activated by NNKAe treatment. However, MTX did not induce these proteins in BEAS-2B cells. We speculate that lower dosage and exposure time for MTX may be ideal for inducing early events in DSBs but may not be sufficient to activate a cascade of effector proteins. Moreover, MTX is also known to have therapeutic applications when used at lower doses [45]. We have also observed the phosphorylation of DNA-PK at T2609 loci which is the most common target for its activation [46]. ATM/ATR often thought to coregulate DNA-PK expression in DSBs, but their choice of involvement still remains inconclusive $[4,11,46]$.

Consistent with our immunofluorescence data, exposure to NNK-Ae triggers the phosphorylation of $\gamma-\mathrm{H} 2 \mathrm{AX}$ as observed in western blot, further confirms the reorganization of histone proteins during DSBs. One hour of AF4 pretreatment significantly inhibits ATR/Chk $1 / \mathrm{p} 53 / \gamma-\mathrm{H} 2 \mathrm{AX}$ signaling, suggesting the mechanism of protective effect possibly through ATR-dependent manner. Further, we also evaluated AF4's involvement in DNA repair mechanisms. AF4 slightly activates DNA-PKcs along with coexpression of KU80 protein in NNK-Ae-treated BEAS-2B cells. The activation of DNA-PKcs primarily enhances NHEJ repair mechanisms [4]. This effect of AF4 was confirmed by using a DNA-PK inhibitor, NU7026. However, more studies are required to claim DNA repairing efficacies of AF4 against NNK-Ae exposure. Overall, our study enlightens to be the first step in evaluating apple flavonoids against oxidative damage induced by carcinogens in bronchial epithelial cells.

In summary, our studies showed that preexposure of apple flavonoids protect BEAS-2B cells challenged against various carcinogens, especially nicotine-derived nitrosamine ketones, by inhibiting DDR signaling and initiate DNA repair mechanisms. Further studies can also give insights to understand the active constituents of AF4 that can also be developed as potential therapeutic adjuvants to reduce the side effects of various cytotoxic or genotoxic chemotherapeutics.

\section{Abbreviations}

AF4: $\quad$ Apple flavonoid fraction

ATM: Ataxia telangiectasia mutated

ATR: $\quad$ ATM-Rad3-related

BEAS-2B: Normal human bronchial epithelial cells

BEGM: Bronchial epithelial cell growth medium

CHK: Check point kinases

DDR: DNA damage response

DMSO: Dimethyl sulfoxide

DNA-PK: DNA-protein kinases

DSBs: $\quad$ DNA double-strand breaks

HR: Homologous recombination

IF: Immunofluorescence

MDC1: Mediators of DNA damage check point 1

MTX: Methotrexate

NHEJ: Nonhomologous end joining

NNK: 4-(Methylnitrosamino)-1-(3-pyridyl-d4)-1-butanone

NNK-Ae: NNK acetate

PI3K: $\quad$ Phosphatidylinositol-3-kinase

ROS: $\quad$ Reactive oxygen species.

\section{Conflicts of Interest}

No conflict of interest was declared by authors on this article. 


\section{Authors' Contributions}

Vazhappilly Cijo George performed all the experiments, analyzed the data, and wrote the preliminary draft of the manuscript. H. P. Vasantha Rupasinghe is the principal investigator who designed the experiments and contributed to the manuscript.

\section{Acknowledgments}

The authors kindly acknowledge the financial support provided by the Discovery Grant program of the Natural Sciences and Engineering Research Council (NSERC) of Canada (2016-05269), Mitacs-Accelerate Program (IT07444), and CoraMedical, Toronto, ON, Canada. The authors would also like to thank Dr. Graham Dellaire of Faculty of Medicine, Dalhousie University for his valuable advices and support in the establishment and validation of the $\gamma$-H2AX assay.

\section{References}

[1] A. J. Davis and D. J. Chen, "DNA double-strand break repair via non-homologous end-joining," Translational Cancer Research, vol. 2, pp. 130-143, 2013.

[2] M. R. Lieber, "The mechanism of double-strand DNA break repair by the nonhomologous DNA end-joining pathway," Annual Review of Biochemistry, vol. 79, pp. 181-211, 2010.

[3] T. Helleday, E. Petermann, C. Lundin, B. Hodgson, and R. A. Sharma, "DNA repair pathways as targets for cancer therapy," Nature Reviews Cancer, vol. 8, pp. 193-204, 2008.

[4] M. Shrivastav, C. A. Miller, L. P. De Haro et al., "DNA-PKcs and ATM co-regulate DNA double-strand break repair," DNA Repair (Amst), vol. 8, pp. 920-929, 2009.

[5] T. Bohgaki, M. Bohgaki, and R. Hakem, "DNA double-strand break signaling and human disorders," Genome Integrity, vol. 1, p. 15, 2010.

[6] P. Rajendran, E. Ho, D. E. Williams, and R. H. Dashwood, "Dietary phytochemicals, HDAC inhibition, and DNA damage/repair defects in cancer cells," Clinical Epigenetics, vol. 3, p. 4, 2011.

[7] A. Rahal, A. Kumar, V. Singh et al., "Oxidative stress, prooxidants, and antioxidants: the interplay," BioMed Research International, vol. 2014, Article ID 761264, 19 pages, 2014.

[8] K. L. Cann and G. G. Hicks, "Regulation of the cellular DNA double-strand break response," Biochemistry and Cell Biology, vol. 85, pp. 663-674, 2007.

[9] A. Marechal and L. Zou, "DNA damage sensing by the ATM and ATR kinases," Cold Spring Harbor Perspectives in Biology, vol. 5, pp. 1-17, 2013.

[10] J. W. Harper and S. J. Elledge, "The DNA damage response: ten years after," Molecular Cell, vol. 28, pp. 739-745, 2007.

[11] H. Yajima, K. J. Lee, and B. P. Chen, "ATR-dependent phosphorylation of DNA-dependent protein kinase catalytic subunit in response to UV-induced replication stress," Molecular and Cellular Biology, vol. 26, pp. 7520-7528, 2006.

[12] J. F. Goodwin, V. Kothari, J. M. Drake et al., "DNA-PKcsmediated transcriptional regulation drives prostate cancer progression and metastasis," Cancer Cell, vol. 28, pp. 97-113, 2015.
[13] U. Moll, R. Lau, M. A. Sypes, M. M. Gupta, and C. W. Anderson, "DNA-PK, the DNA-activated protein kinase, is differentially expressed in normal and malignant human tissues," Oncogene, vol. 18, pp. 3114-3126, 1999.

[14] V. C. George, G. Dellaire, and H. P. V. Rupasinghe, "Plant flavonoids in cancer chemoprevention: role in genome stability," The Journal of Nutritional Biochemistry, vol. 45, pp. 1-14, 2017.

[15] P. G. Keddy, K. Dunlop, J. Warford et al., "Neuroprotective and anti-inflammatory effects of the flavonoid-enriched fraction AF4 in a mouse model of hypoxic-ischemic brain injury," PLoS One, vol. 7, article e51324, 2012.

[16] J. Warford, R. Quinton, D. Jones et al., "The flavonoidenriched fraction AF4 suppresses neuroinflammation and promotes restorative gene expression in a mouse model of experimental autoimmune encephalomyelitis," Journal of Neuroinflammation, vol. 268, pp. 71-83, 2014.

[17] S. Sudan and H. P. V. Rupasinghe, "Flavonoid-enriched apple fraction AF4 induces cell cycle arrest, DNA topoisomerase II inhibition, and apoptosis in human liver cancer HepG2 cells," Nutrition and Cancer, vol. 66, pp. 1237-1246, 2014.

[18] P. Wang, S. M. Henning, and D. Heber, "Limitations of MTT and MTS-based assays for measurement of antiproliferative activity of green tea polyphenols," PLoS One, vol. 5, article e10202, 2010.

[19] H. Wang and J. A. Joseph, "Quantifying cellular oxidative stress by dichlorofluorescein assay using microplate reader," Free Radical Biology \& Medicine, vol. 27, pp. 612-616, 1999.

[20] A. Ivashkevich, C. E. Redon, A. J. Nakamura, R. F. Martin, and O. A. Martin, "Use of the gamma-H2AX assay to monitor DNA damage and repair in cancer research," Cancer Letters, vol. 327, pp. 123-133, 2012.

[21] V. C. George, D. R. Naveen Kumar, P. K. Suresh, S. Kumar, and R. A. Kumar, "Comparative studies to evaluate relative in vitro potency of luteolin in inducing cell cycle arrest and apoptosis in HaCaT and A375 cells," Asian Pacific Journal of Cancer Prevention, vol. 14, pp. 631-637, 2013.

[22] V. Lobo, A. Patil, A. Phatak, and N. Chandra, "Free radicals, antioxidants and functional foods: impact on human health," Pharmacognosy Reviews, vol. 4, pp. 118-126, 2010.

[23] E. Birben, U. M. Sahiner, C. Sackesen, S. Erzurum, and O. Kalayci, "Oxidative stress and antioxidant defense," World Allergy Organization Journal, vol. 5, pp. 9-19, 2012.

[24] E. P. Rogakou, W. Nieves-Neira, C. Boon, Y. Pommier, and W. M. Bonner, "Initiation of DNA fragmentation during apoptosis induces phosphorylation of $\mathrm{H} 2 \mathrm{AX}$ histone at serine 139," The Journal of Biological Chemistry, vol. 275, pp. 9390-9395, 2000.

[25] A. R. Collins, "The comet assay for DNA damage and repair: principles, applications, and limitations," Molecular Biotechnology, vol. 26, pp. 249-261, 2004.

[26] J. P. Silva, A. C. Gomes, and O. P. Coutinho, "Oxidative DNA damage protection and repair by polyphenolic compounds in PC12 cells," European Journal of Pharmacology, vol. 601, pp. 50-60, 2008.

[27] E. Willmore, S. de Caux, N. J. Sunter et al., "A novel DNAdependent protein kinase inhibitor, NU7026, potentiates the cytotoxicity of topoisomerase II poisons used in the treatment of leukemia," Blood, vol. 103, pp. 4659-4665, 2004.

[28] S. A. Langie, G. Koppen, D. Desaulniers et al., "Causes of genome instability: the effect of low dose chemical exposures 
in modern society," Carcinogenesis, vol. 36, Supplement 1, pp. S61-S88, 2015.

[29] S. K. Das, "Free radicals, antioxidants and nutraceuticals in health, disease \& radiation biology. Preface," Indian Journal of Biochemistry \& Biophysics, vol. 49, pp. 291-292, 2012.

[30] K. Wolfe, X. Wu, and R. H. Liu, "Antioxidant activity of apple peels," Journal of Agricultural and Food Chemistry, vol. 51, pp. 609-614, 2003.

[31] S. Sekhon-Loodu, S. N. Warnakulasuriya, H. P. V. Rupasinghe, and F. Shahidi, "Antioxidant ability of fractionated apple peel phenolics to inhibit fish oil oxidation," Food Chemistry, vol. 140, pp. 189-196, 2013.

[32] A. Murakami, "Dose-dependent functionality and toxicity of green tea polyphenols in experimental rodents," Archives of Biochemistry and Biophysics, vol. 557, pp. 3-10, 2014.

[33] E. J. Calabrese, "Converging concepts: adaptive response, preconditioning, and the Yerkes-Dodson law are manifestations of hormesis," Ageing Research Reviews, vol. 7, pp. 8-20, 2008.

[34] M. H. Hanigan and P. Devarajan, "Cisplatin nephrotoxicity: molecular mechanisms," Cancer Therapy, vol. 1, pp. 47-61, 2003.

[35] J. Xue, S. Yang, and S. Seng, "Mechanisms of cancer induction by tobacco-specific NNK and NNN," Cancers (Basel), vol. 6, pp. 1138-1156, 2014.

[36] V. C. George, D. R. Kumar, P. K. Suresh, and R. A. Kumar, "Antioxidant, DNA protective efficacy and HPLC analysis of Annona muricata (soursop) extracts," Journal of Food Science and Technology, vol. 52, pp. 2328-2335, 2015.

[37] C. R. Clapier and B. R. Cairns, "The biology of chromatin remodeling complexes," Annual Review of Biochemistry, vol. 78, pp. 273-304, 2009.

[38] P. L. Olive and J. P. Banath, "Kinetics of H2AX phosphorylation after exposure to cisplatin," Cytometry. Part B, Clinical Cytometry, vol. 76, pp. 79-90, 2009.

[39] T. Tanaka, A. Kurose, X. Huang, W. Dai, and Z. Darzynkiewicz, "ATM activation and histone H2AX phosphorylation as indicators of DNA damage by DNA topoisomerase I inhibitor topotecan and during apoptosis," Cell Proliferation, vol. 39, pp. 49-60, 2006.

[40] M. Lohani, M. Ahuja, M. A. Buabeid et al., "Anti-oxidative and DNA protecting effects of flavonoids-rich Scutellaria lateriflora," Natural Product Communications, vol. 8, pp. 14151418, 2013.

[41] R.H.Hussein and F. K. Khalifa, “The protective role of ellagitannins flavonoids pretreatment against $\mathrm{N}$-nitrosodiethylamine induced-hepatocellular carcinoma," Saudi Journal of Biological Sciences, vol. 21, pp. 589-596, 2014.

[42] J. Zhang, X. Wang, K. E. Bove, and M. Xu, "DNA fragmentation factor 45-deficient cells are more resistant to apoptosis and exhibit different dying morphology than wild-type control cells," The Journal of Biological Chemistry, vol. 274, pp. 3745037454, 1999.

[43] P. Dong, X. Fu, X. Wang, W. M. Wang, W. M. Cao, and W. Y. Zhang, "Protective effects of sesaminol on BEAS-2B cells impaired by cigarette smoke extract," Cell Biochemistry and Biophysics, vol. 71, pp. 1207-1213, 2015.

[44] J. Smith, L. M. Tho, N. Xu, and D. A. Gillespie, "The ATM-Chk2 and ATR-Chk1 pathways in DNA damage signaling and cancer," Advances in Cancer Research, vol. 108, pp. 73-112, 2010.
[45] B. N. Cronstein, "Low-dose methotrexate: a mainstay in the treatment of rheumatoid arthritis," Pharmacological Reviews, vol. 57, pp. 163-172, 2005.

[46] B. P. Chen, N. Uematsu, J. Kobayashi et al., "Ataxia telangiectasia mutated (ATM) is essential for DNA-PKcs phosphorylations at the Thr-2609 cluster upon DNA double strand break," The Journal of Biological Chemistry, vol. 282, pp. 6582-6587, 2007. 


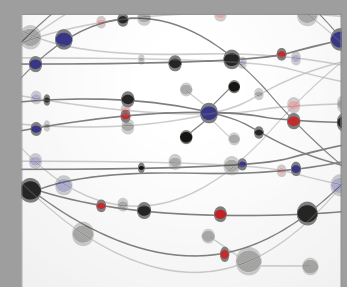

The Scientific World Journal
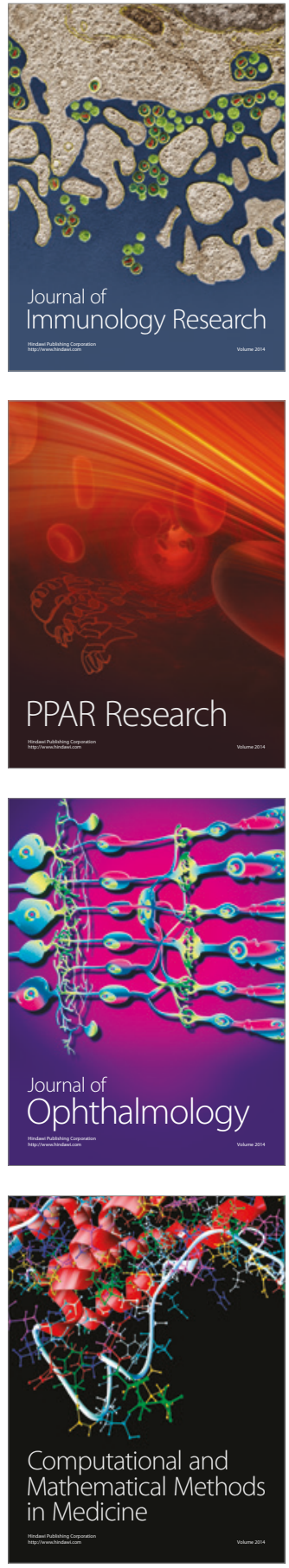

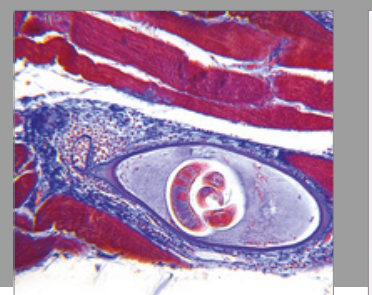

Gastroenterology Research and Practice
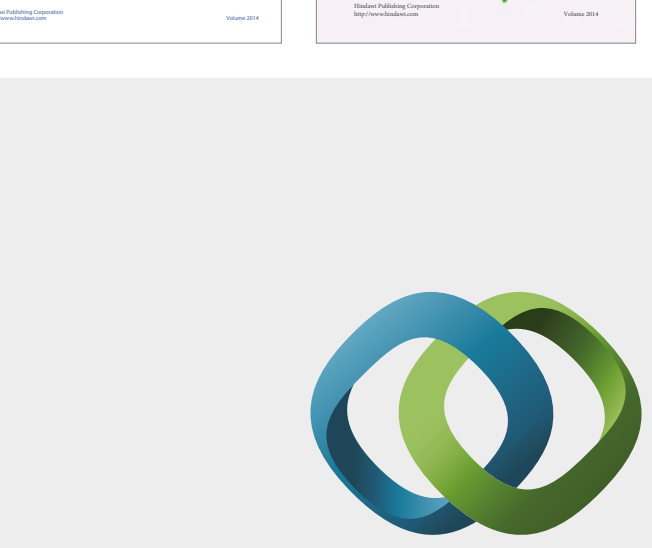

\section{Hindawi}

Submit your manuscripts at

https://www.hindawi.com
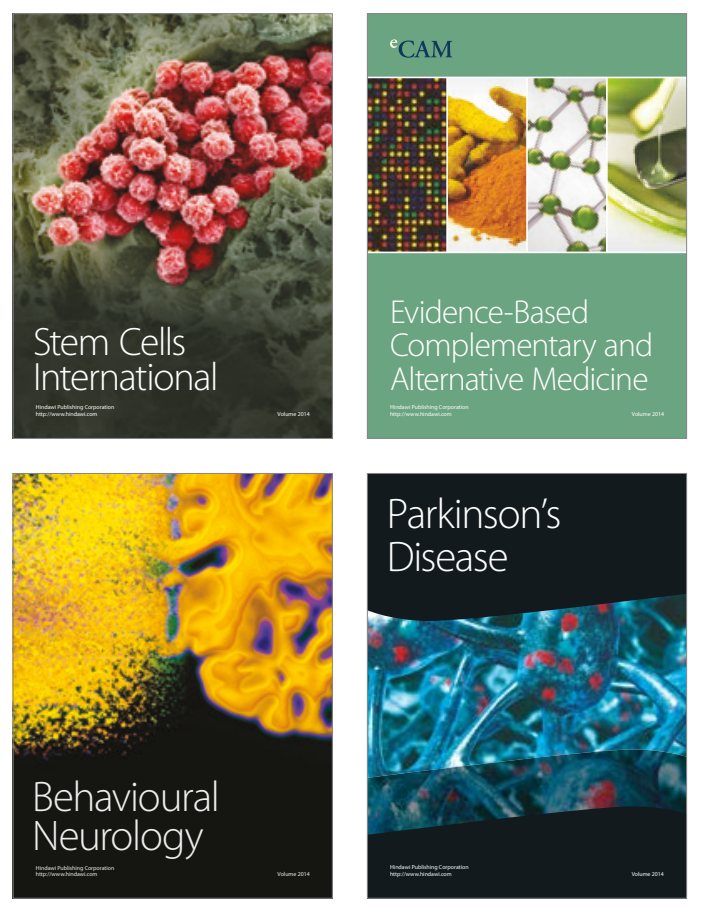
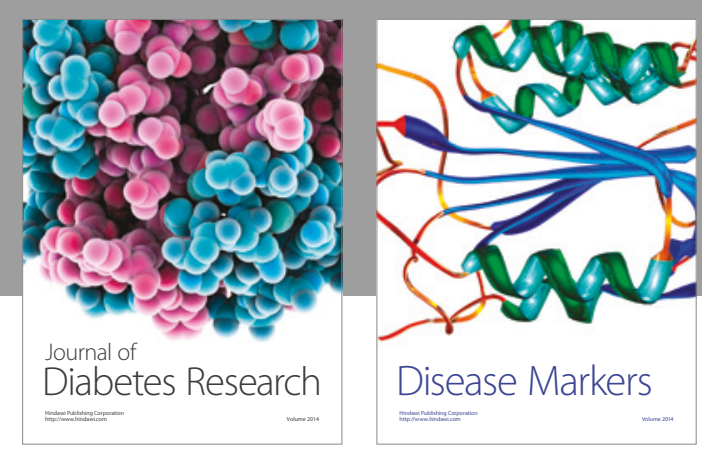

Disease Markers
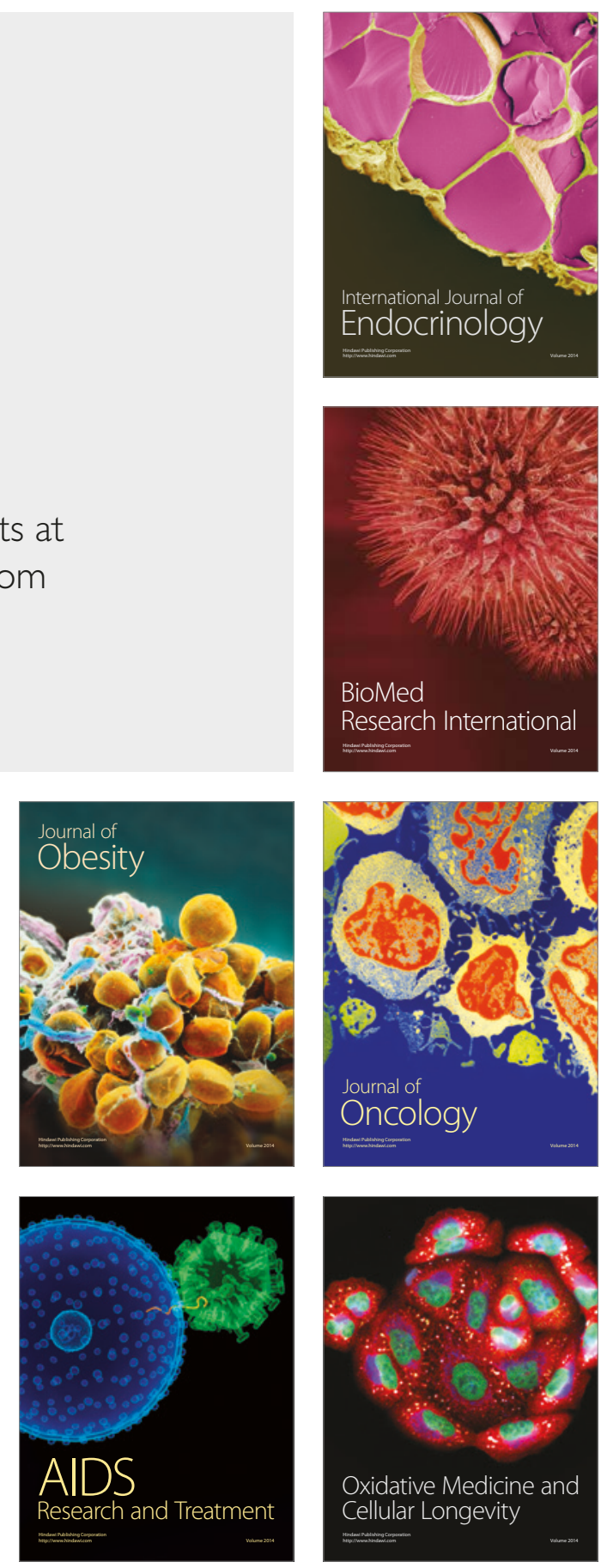